\title{
Acetic acid alleviates the inflammatory response and liver injury in septic mice by increasing the expression of TRIM40
}

\author{
HONGGUANG YANG, LAN MENG, DENGBIN AI, NIANGUO HOU, \\ HUI LI, XUNJUN SHUAI and XIAOYAN PENG
}

\author{
Department of Anesthesiology, Qingdao Municipal Hospital, Qingdao, Shandong 266011, P.R. China
}

Received May 14, 2018; Accepted December 3, 2018

DOI: $10.3892 /$ etm.2019.7274

\begin{abstract}
Sepsis remains a significant health care issue in clinical practice due to its high mortality rate and healthcare cost, despite extensive efforts to better understand the pathophysiology of sepsis. The systemic inflammatory response often leads to severe liver injury, even acute liver dysfunction and failure. Acetic acid, as a type of chemical compound, has been reported to be an emerging drug for improving metabolic syndrome and inhibiting inflammation in rats and human. To verify the effects of acetic acid in protecting the liver and reducing the inflammatory response, a septic mouse model was established by cecal ligation and puncture (CLP), and then the CLP-model mice were treated with acetic acid or PBS. Following the treatment, it was determined that, in CLP-model mice, acetic acid could alleviate the inflammatory response by decreasing the expression of cytokines including interleukin- 6 and tumor necrosis factor- $\alpha$. Additionally, acetic acid also alleviated the liver injury, and the levels of alanine aminotransaminase, aspartate aminotransferase, Toll-like receptor (TLR) 4 and nuclear factor- $\kappa \mathrm{B}(\mathrm{NF}-\kappa \mathrm{B})$ were decreased. The expression of tripartite motif-containing protein (TRIM)40 was also upregulated significantly. Therefore, the authors of the current study hypothesized that acetic acid could decrease the inflammatory response by increasing the expression of TRIM40 and TRIM40 may regulate the activity of the TLR4 signaling pathway. To further illustrate the interaction between TRIM40 and the TLR4 signaling pathway, the authors collected macrophages from the peritoneal cavity by intraperitoneally administering mice with $5 \mathrm{ml}$ ice-cold normal saline. Following the collection, peritoneal macrophages were treated with acetic acid, TRIM40 small interfering RNA or PBS. It was demonstrated that acetic acid upregulated the expression of TRIM40. When TRIM40 was silenced, the protective effect
\end{abstract}

Correspondence to: Professor Xiaoyan Peng, Department of Anesthesiology, Qingdao Municipal Hospital, 1 Jiaozhou Road, Qingdao, Shandong 266011, P.R. China

E-mail: xiaoyan_peng123@163.com

Key words: sepsis, tripartite motif-containing protein 40, liver injury, nuclear factor $\mathrm{NF}-\kappa \mathrm{B}$, acetic acid of acetic acid would be reversed as well. The results suggested that TRIM40 could act on and downregulate the activity of the TLR4 signaling pathway. TRIM40 is possibly the major target for acetic acid, which may function as a protective factor in septic mice.

\section{Introduction}

Sepsis is a dysregulated host response to infection, which could result in severe multiorgan dysfunctions and high mortality rates (1-3). Treating sepsis and sepsis-associated multiorgan failure remains challenging for clinicians and scientists (4). Even though an increasing number of studies have been conducted, the pathophysiology of sepsis in humans remains unclear $(5,6)$. According to previous studies, sepsis influenced the prognosis of one-third of all patients on admission or during their stay in the intensive care unit and the mortality rate of these patients reached $25-35 \%$ (7,8). In the United States, sepsis is ranked as the tenth leading cause of mortality and accounts for approximately 24 billion dollars of total hospital costs every year (9). As a result, more effective drugs and new treatment methods for sepsis are imperative to reducing the morbidity and mortality rates associated with sepsis.

Systemic inflammatory response syndrome is common in sepsis and is usually initiated by severe infection or acute injury $(1,10,11)$. This systemic inflammatory response has been revealed to often lead to dysfunction in multiple organs, including the liver, lungs, kidneys and heart $(1,12)$. Among these organs, sepsis-associated liver dysfunction and failure are crucial to survival rate, and are connected with high mortality rate (13). According to the French EPISEPSIS (EPIdemiology of SEPSIS) study group, the incidence rate of liver dysfunction (hepatic score $>0$ ) and liver failure (hepatic score of 3 or 4 ) were 46.6 and $6.3 \%$, respectively (13). However, in another clinical trial, which involved 312 patients in septic shock, the rate of acute liver failure was even reported to be $20 \%$ (14). Therefore, more attention should be paid to decreasing sepsis-associated liver dysfunction and failure.

Toll-like receptors (TLRs), a type of membrane receptor, which can recognize pathogen-associated molecular patterns and connect to the body's immune response system (15). Lipopolysaccharide (LPS) is the main component of endotoxins and can stimulate the release of multiple inflammatory mediators, which promote the progression of systemic inflammatory 
response syndrome (16). Studies revealed that LPS could bind to TLR4 and TLR signaling pathways may be involved in modulating allergic immune responses $(17,18)$. Also, TLR4 is the major pattern recognition receptor for detecting endotoxins (19). When endotoxins activate TLR4, nuclear factor- $\kappa B$ $(\mathrm{NF}-\mathrm{\kappa B})$ activates (19). NF- $\mathrm{KB}$ is the downstream intracellular molecule, which is involved in activating the expression of many pro-inflammatory genes, including interleukin (IL)-1 $\beta$ and tumor necrosis factor (TNF)- $\alpha$ (20). As a result, reduce liver dysfunction and liver failure induced by LPS may be achieved by regulating TLR signaling pathways.

The structure of the tripartite motif-containing protein (TRIM) protein family is composed of three zinc-binding domains: RING, B-box type 1 and B-box type 2, followed by a coiled-coil region; it is also known as the RBCC family (21). The majority of TRIM proteins have been reported to be involved in the ubiquitination process (22). However, studies also revealed that some TRIM family members are involved in different cellular processes, including apoptosis, cell growth, transcriptional regulation and oncogenesis (23-25). In a past study by our group, the authors demonstrated that the TRIM family protein, TRIM40, was highly expressed in the liver tissue of cecal ligation and puncture (CLP)-model mice treated with acetic acid. Furthermore, the TLR4 signaling pathway was downregulated, and the expression levels of NF- $\mathrm{kB}$, IL-6 and TNF- $\alpha$ were decreased. With the purpose of elucidating the molecular function of TRIM40 in the liver of CLP models, and illustrating the protective mechanism of acetic acid in liver dysfunction and liver failure, the authors decided to perform further studies. As a result, the authors identified the minimum dose of acetic acid that inhibited inflammatory responses in CLP models by upregulating the expression of TRIM40, which may regulate the activity of the TLR4 signaling pathway.

\section{Materials and methods}

Animals. All animals were fed based on the Principles of Laboratory Animal Care formulated by the National Institutes of Health (26) and guidelines of the Institutional Animal Care and Use Committee of Qingdao Municipal Hospital (Qingdao, China) (27). A total of 48 male C57BL/6 mice (6-8 weeks old) weighing $20 \pm 2 \mathrm{~g}$ were obtained from the School of Medicine, Qingdao University (Qingdao, China). Mice were housed in a specific pathogen-free animal facility under controlled environmental conditions of $22 \pm 2^{\circ} \mathrm{C}$ and a $12 \mathrm{~h}$ light-dark cycle. Mice were fed with a standard pellet diet and water. The experiment was approved by the Ethics Committee in Qingdao University.

Acquisition and culture of peritoneal macrophages. First, the mice were intraperitoneally administered with $5 \mathrm{ml}$ ice-cold normal saline and after $6 \mathrm{~h}$, peritoneal cell suspensions were collected with the same needle. The collected peritoneal cells suspensions were centrifuged at $1,000 \mathrm{xg}$ for $3 \mathrm{~min}$ at $4^{\circ} \mathrm{C}$. Then the supernatant was removed and the sediment was resuspended in PBS, and centrifuge again at $1,000 \mathrm{x} \mathrm{g}$ for $3 \mathrm{~min}$ at $4^{\circ} \mathrm{C}$. The collected peritoneal cells were suspended in Dulbecco's modified Eagle's medium (DMEM; Hyclone; GE Healthcare Life Sciences, Logan, UT, USA) supplemented with $10 \%$ fetal bovine serum (FBS; Gibco; Thermo Fisher
Scientific, Inc., Waltham, MA, USA) for $24 \mathrm{~h}$ at $37^{\circ} \mathrm{C}, 50 \mathrm{U} / \mathrm{ml}$ penicillin and $50 \mu \mathrm{g} / \mathrm{ml}$ streptomycin. The number of cells was counted using a cell counting chamber (Wuxi Devan Scientific Ltd., Co., Wuxi, China). According to reports, after incubating the peritoneal cells for $1 \mathrm{~h},>98 \%$ of adherent cells in culture dishes were identified as macrophages due to the observation of $\mathrm{Fc}$ receptor-mediated phagocytosis and the Giemsa staining performed $(28,29)$.

RNA interference. TRIM40 small interfering (si)RNA (siTRIM40; 5'-CTTCTCTGAGGCAGTAACA-3') and negative control siRNA (siNC; 5'-TTCTCCGAACGT GTCACGT-3') were bought from Novus Biologicals, LLC (Littleton, CO, USA). Peritoneal macrophages were transfected with $50 \mathrm{nM}$ siRNA or siNC using Lipofectamine ${ }^{\circledR}$ 2000 (Invitrogen; Thermo Fisher Scientific, Inc.) according to the manufacturer's protocol. The knockdown efficiency was assessed by RT-qPCR after $48 \mathrm{~h}$ of transfection.

Experimental procedures. Sepsis was induced by CLP as described by Rittirsch et al (30). To investigate whether acetic acid alleviates liver injury and inflammation induced caused by CLP, mice were randomly divided into four groups (n=6/group): Control, control + acetic acid, CLP + PBS and CLP + acetic acid. Animals were anaesthetized by $1.2 \%$ sevoflurane (Jiangsu Hengrui Medicine Co., Ltd., Lianyungang, China) prior to surgery. Mice in the control group were intravenously injected with PBS following a sham surgery (the abdomen was opened, but CLP was not performed), mice in the control + acetic acid group were intravenously injected with acetic acid $(0.1 \mathrm{mmol} / \mathrm{kg}$; Sigma-Aldrich, Merck KGaA, Darmstadt, Germany) following a sham surgery, mice in the CLP + PBS group were intravenously injected with $0.1 \mathrm{ml}$ PBS following CLP, and mice in the CLP + acetic acid group were intravenously injected with PBS and acetic acid following CLP. A total of $12 \mathrm{~h}$ after the drug treatments, mice were sacrificed by cervical dislocation under anesthesia (1.2\% sevoflurane) and blood was withdrawn from the heart to estimate liver injury by measuring alanine aminotransferase (ALT), aspartate aminotransferase (AST) and total bilirubin (TBiL) levels. At the same time, ascites was collected, and IL-6, IL-10 and TNF- $\alpha$ levels in the ascites were also detected. Livers were removed and stored at $-80^{\circ} \mathrm{C}$ for further experiments, and partial liver specimens were submerged in $10 \%$ neutral formalin prior to being processed for histopathological analysis. To draw the survival curve, the aforementioned protocol was performed and mortality was recorded between days 1-7 after CLP, and survivors were monitored once every day for an additional 3 weeks to verify that no late mortalities occurred (10 mice/group).

To investigate the involvement of TRIM40 in the TLR4 signaling pathway, the peritoneal macrophages were divided into six groups as follows: Control, control + acetic acid, LPS, LPS + acetic acid, LPS + acetic acid + siTRIM40 and LPS + siTRIM40. Cells in the control group were treated with $0.1 \mathrm{ml} \mathrm{PBS}$; cells in the control + acetic acid group were treated with acetic acid $(0.1 \mathrm{mmol} / \mathrm{ml})$; cells in the LPS group were treated with LPS $(0.1 \mathrm{mmol} / \mathrm{ml}$; Sigma-Aldrich; Merck $\mathrm{KGaA})$; cells in the LPS + acetic acid group were treated with LPS $(0.1 \mathrm{mmol} / \mathrm{ml})+$ acetic acid $(0.1 \mathrm{mmol} / \mathrm{ml})$; cells 
in the LPS + acetic acid + siRNA group were treated with LPS $(0.1 \mathrm{mmol} / \mathrm{ml})+$ acetic acid $(0.1 \mathrm{mmol} / \mathrm{ml})+$ siTRIM40 (50 nM); cells in the LPS + siTRIM40 group were treated with LPS $(0.1 \mathrm{mmol} / \mathrm{ml})+$ siTRIM40. Acetic acid and LPS were dissolved in sterile PBS. After 3 days of drug treatment in cell incubator $\left(37^{\circ} \mathrm{C}, 5 \% \mathrm{CO}_{2}\right)$, the medium was collected to measure the concentration of cytokines, including TNF- $\alpha$, IL-6 and IL-10. The expression levels of TRIM40, TLR4 and $\mathrm{NF}-\kappa \mathrm{B}$ in macrophages were analyzed by reverse transcription-quantitative polymerase chain reaction (RT-qPCR) analysis and western blotting.

RT-qPCR analysis. To evaluate the mRNA levels of inflammatory mediators, mice were sacrificed under anesthesia (1.2\% sevoflurane) after drug treatment for $12 \mathrm{~h}$ and livers were frozen. Total RNA was extracted from the liver cells using an Ultrapure RNA kit (Beijing ComWin Biotech, Co., Ltd., Beijing, China), and cDNA was synthesized using the RevertAid $^{\mathrm{TM}}$ first strand cDNA synthesis kit (Thermo Fisher Scientific, Inc.). RT-qPCR was performed as previously reported (31). The reaction conditions for RT-qPCR were as follows: Pre-denaturation at $95^{\circ} \mathrm{C}$ for $30 \mathrm{sec}$, and 40 cycles of $95^{\circ} \mathrm{C}$ for $10 \mathrm{sec}$ and $60^{\circ} \mathrm{C}$ for $30 \mathrm{sec}$. The melting curve was at $95^{\circ} \mathrm{C}$ for $15 \mathrm{sec}, 60^{\circ} \mathrm{C}$ for $60 \mathrm{sec}$ and $95^{\circ} \mathrm{C}$ for $15 \mathrm{sec}$. The primer sequences used in the current study were as follows: TRIM40, forward 5'-ATGGGCTCTCTTGACAAGGAC-3' and reverse 5'-ACTGAAGCCTTATCCATGTGC-3'; NF- $\kappa$ B, forward 5'-CAAGCGAGGAGGGGACGTG-3' and reverse 5'-CCC CCAGAGCCTCCACCC-3'; and TLR4, forward 5'-GCCTTT CAGGGAATTAAGCTCC-3' and reverse 5'-GATCAACCG ATGGACGTGTAAA-3'; and GAPDH, forward 5'-CTGGGC TACACTGAGCACC-3' and reverse 5'-AAGTGGTCGTTG AGGGCAATG-3'.

Western blotting. Total intracellular protein was isolated using RIPA buffer supplemented with protease inhibitor cocktail (both Sigma-Aldrich; Merck KGaA). The protein concentrations were determined using a Bicinchoninic Acid Protein Assay kit (Pierce; Thermo Fisher Scientific, Inc.). Protein samples (16-20 $\mu \mathrm{g} /$ lane) separated by SDS-PAGE were loaded on $8-12 \%$ polyacrylamide gels (Beyotime Institute of Biotechnology, Haimen, China) and then transferred to polyvinylidene fluoride membranes (EMD Millipore, Billerica, MA, USA) using the Semi-Dry Trans-Blot Cell (Bio-Rad Laboratories, Inc., Hercules, CA, USA). Following the transfer, the membranes were blocked by $3 \%$ bovine serum albumin (Sigma-Aldrich; Merck KGaA) in TBS for $1 \mathrm{~h}$ at room temperature. Blots were incubated with primary antibodies overnight at $4{ }^{\circ} \mathrm{C}$. The primary antibodies were as follows: TLR4 (1:2,500; cat. no. IMG-5031A; Novus Biologicals, LLC), NF-кB (cat. no. SAB4501993), $\beta$-actin (cat. no. A1978; both 1:5,000; Sigma-Aldrich; Merck KGaA) and TRIM40 (1:5,000; cat. no. ab156583, Abcam, Cambridge, UK). The bands were then observed by enhanced chemiluminescent reagents (Shanghai Yeasen Biotech Co., Ltd., Shanghai, China) and exposed to X-ray films (Bio-Rad Laboratories, Inc.).

Histological analysis. Following the sacrifice of the mice, liver tissues were sampled from the left lobe and quickly fixed in

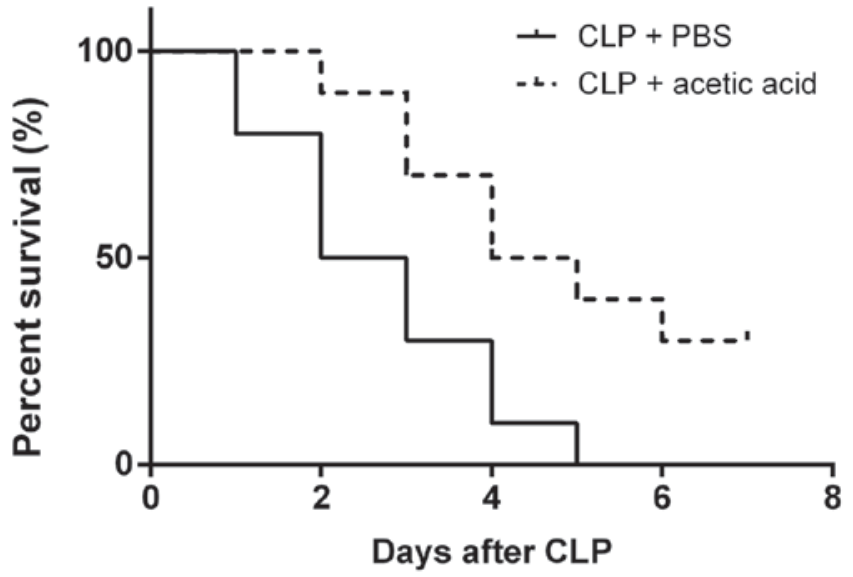

Figure 1. Acetic acid improves the survival rate of CLP-model mice. Kaplan-Meier survival curves of mice following CLP and the intravenous administration of PBS or $0.1 \mathrm{mmol} / \mathrm{kg}$ acetic acid ( $\mathrm{n}=10 \mathrm{mice} / \mathrm{group}$ ). CLP, cecal ligation and puncture.

$10 \%$ neutral buffered formalin at room temperature for $24 \mathrm{~h}$. Then the samples would be embedded in paraffin and serially cut into $5-\mu$ m-thick sections. Sections were stained with hematoxylin and eosin at room temperature for $30 \mathrm{~min}$, then the sections were observed using a phase contrast microscope at a magnification of $\mathrm{x} 200$.

ELISA and blood assays. The IL-6 (cat. no. BGK08505), IL-10 (cat. no. BGK18893) and TNF- $\alpha$ (cat. no. BGK06804) levels in ascites were detected using ELISA kits (PeproTech, Inc., Rocky Hill, NJ, USA) as previously reported (32). The values are recorded as ng/mg of protein. To measure ALT, AST and TBiL levels, blood assays were performed by a biochemical automatic analyzer (Vitros750; Johnson \& Johnson, New Brunswick, NJ, USA).

Statistical analysis. All the statistical analyses were performed by SPSS 23.0 software (IBM Corp., Armonk, NY, USA) and graphs were drawn using GraphPad Prism 5.01 (GraphPad Software, Inc., La Jolla, CA, USA). All values are presented as mean \pm standard deviation. Kaplan-Meier survival curves were generated and group comparisons were based on the log-rank test. Comparisons between different groups were conducted using the Student's t-test for two independent groups or one-way analysis of variance followed by Tukey's test for multiple independent groups. $\mathrm{P}<0.05$ indicated that the difference between groups was statistically significant.

\section{Results}

Acetic acid protects mice against sepsis-induced mortality and alleviates inflammation induced by sepsis. To investigate the protective effects of acetic acid in reducing CLP-induced mortality, the survival rate was monitored for 7 days. In the CLP + PBS group, the survival rate on the first day of observation was $80 \%$ and all mice succumbed by day 6 after CLP ( $\mathrm{P}=0.0106$; Fig. 1). In the CLP + acetic acid group, the survival rate on day 7 was observed as $30 \%$ and three mice continued to survive for 7 days. Treatment of acetic acid improved the survival rate compared with the CLP + PBS 

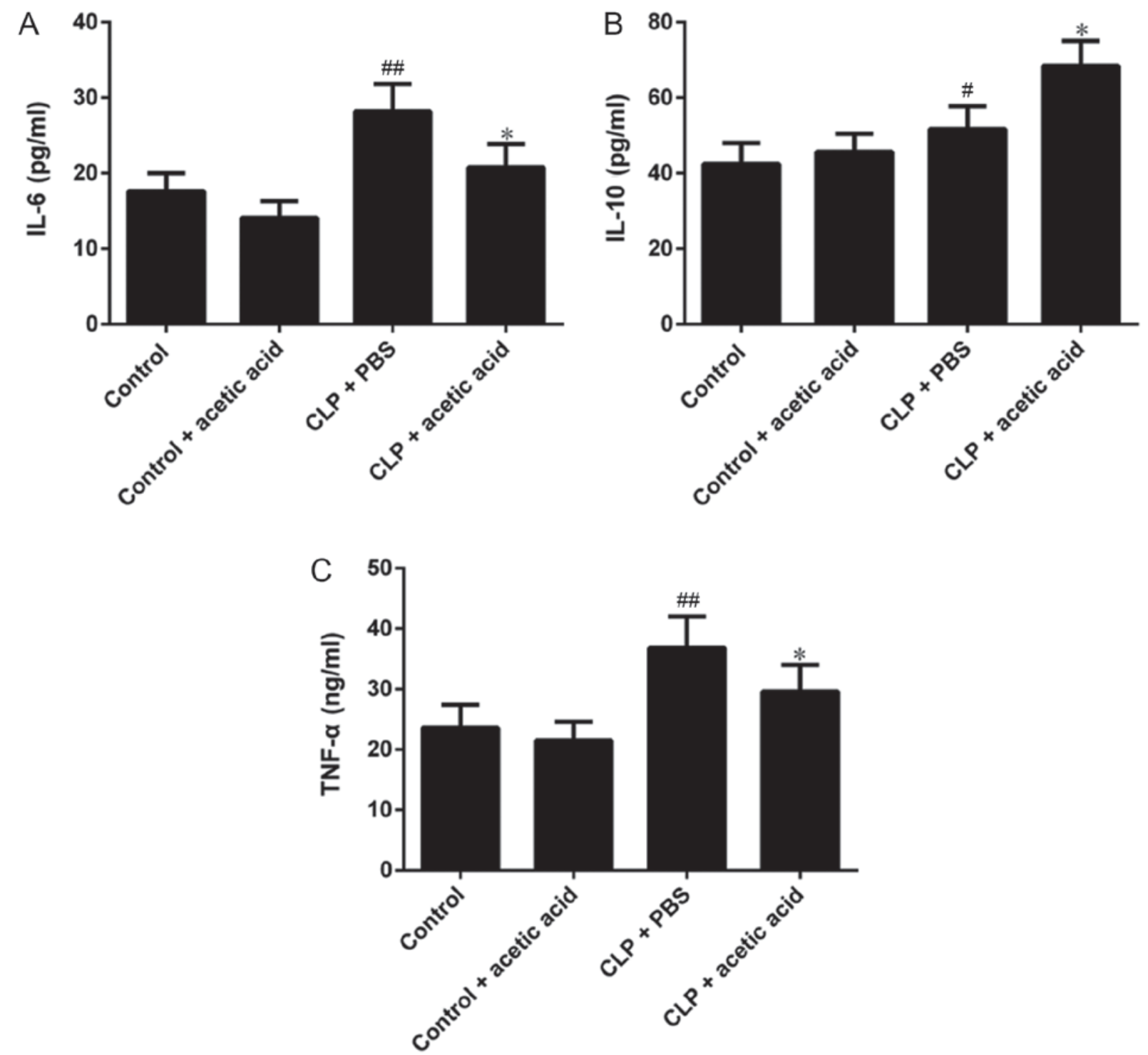

Figure 2. Acetic acid decreases the concentration of inflammatory cytokines in the serum of CLP-model mice. Serum (A) IL-6, (B) IL-10 and (C) TNF- $\alpha$ levels were detected by ELISA $12 \mathrm{~h}$ after PBS and acetic acid treatment ( $\mathrm{n}=6$ mice/group). Results are presented as mean \pm standard deviation. ${ }^{*} \mathrm{P}<0.05 \mathrm{vs}$. the CLP + PBS group. ${ }^{\#} \mathrm{P}<0.05,{ }^{\# \#} \mathrm{P}<0.01$ vs. the control group. CLP, cecal ligation and puncture; IL, interleukin; TNF- $\alpha$, tumor necrosis factor $\alpha$.

group. The median survival in the CLP + PBS group was 2.5 days compared with 4.5 days in the CLP + acetic acid group. Then the authors evaluated whether acetic acid could decrease sepsis-induced inflammation by measuring serum IL-6, IL-10 and TNF- $\alpha$ levels. According to the results, it was determined that serum IL-6, IL-10 and TNF- $\alpha$ levels were $17.6 \pm 2.4 \mathrm{pg} / \mathrm{ml}, 42.4 \pm 5.6 \mathrm{pg} / \mathrm{ml}$ and $23.6 \pm 3.8 \mathrm{ng} / \mathrm{ml}$ in the control group, respectively (Fig. 2). CLP significantly increased serum IL-6, IL-10 and TNF- $\alpha$ levels by 1.6-, 1.2and 1.6-fold compared with the control group, respectively. In the CLP + acetic acid group, serum IL- 6 and TNF- $\alpha$ levels were significantly downregulated 26 and $20 \%$, respectively, while the serum IL-10 level was significantly upregulated $32 \%$ compared with the CLP + PBS group. The results suggested that acetic acid decreased the synthesis of inflammatory cytokines, thus alleviating inflammation induced by sepsis. Also, no significant changes in serum concentrations were identified between the control and control + acetic acid groups.
Histological analysis of liver tissue and detection of liver injury. To explore whether acetic acid could alleviate liver injury induced by sepsis, serum ALT, AST and TBiL levels were detected. In control group, serum ALT, AST and TBiL levels were $35.5 \pm 4.6 \mathrm{U} / 1,46.9 \pm 4.3 \mathrm{U} / 1$ and $7.2 \pm 0.6 \mu \mathrm{mol} / 1$, respectively (Fig. 3). No significant differences were identified between the control + acetic acid and control groups. CLP significantly increased serum ALT, AST and TBiL levels by 1.4-, 1.4- and 2.2-fold compared with the control group, respectively. Treatment with acetic acid attenuated changes in ALT, AST and TBiL levels. In the CLP + acetic acid group, serum ALT, AST and TBiL levels decreased significantly compared with the CLP + PBS group, respectively.

Histological evaluations revealed that the livers in the control group possessed normal cell structures (Fig. 4A). In comparison with the control group, marked histopathological changes were observed in the CLP + PBS and CLP + acetic acid groups, including inflammatory cells infiltration and cell death (Fig. 4B and C). The livers from mice in the control + acetic 

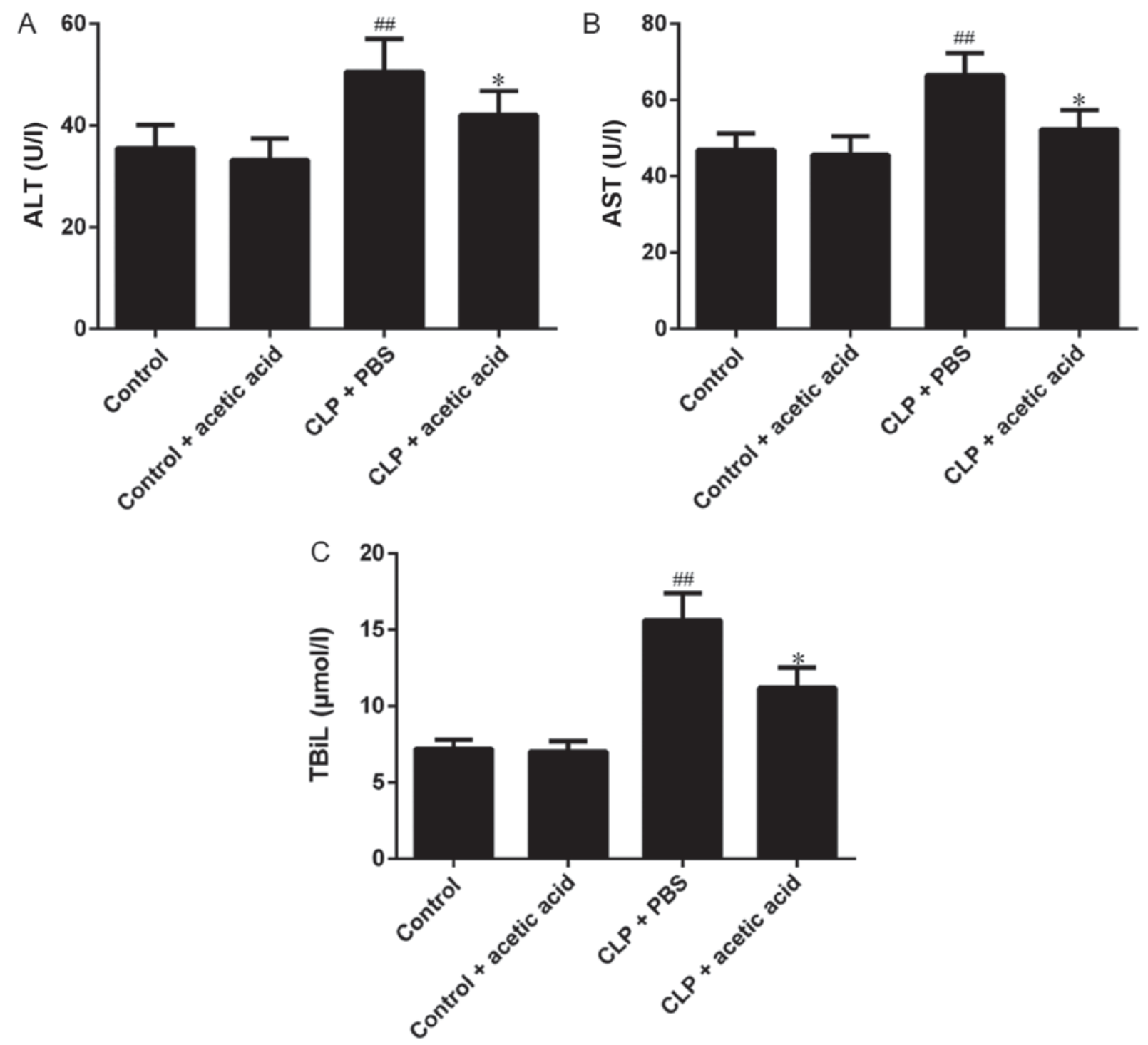

Figure 3. Acetic acid decreases the concentration of liver enzymes in the serum of CLP-model mice. Serum (A) ALT, (B) AST and (C) TBiL levels were detected by a biochemical automatic analyzer $12 \mathrm{~h}$ after PBS and acetic acid treatment ( $\mathrm{n}=6$ mice/group). Results are presented as mean \pm standard deviation. ${ }^{*} \mathrm{P}<0.05$ vs. the CLP + PBS group. ${ }^{\# \#} \mathrm{P}<0.01$ vs. the control group. CLP, cecal ligation and puncture; ALT, alanine aminotransferase; AST, aspartate aminotransferase; TBiL, total bilirubin.

acid group retained normal cell structures (Fig. 4D). Acetic acid treatment attenuated the pathological changes observed in the CLP + PBS group. These results suggested that acetic acid could alleviate liver injury induced by sepsis in mice.

Acetic acid upregulates the expression of TRIM40 and inhibits the expression of $N F-\kappa B$ and TLR4 in liver. The authors of the current study assessed the expression levels of TRIM40, $N F-\kappa B$ and TLR4 in livers to verify if acetic acid could influence TRIM40 expression and the TLR4 signaling pathway. According to the results of RT-qPCR analysis and western blot analysis, it was demonstrated that mRNA levels of NF- $\kappa B$ and TLR4 significantly increased by 1.9- and 1.6-fold, respectively, while the mRNA level of TRIM40 significantly decreased by $28 \%$ compared with the control group (Fig. 5A). Furthermore, in the CLP + acetic acid group, the expression of TRIM40 was significantly higher while the expression levels of NF- $\kappa \mathrm{B}$ and TLR4 were significantly lower compared with the CLP + PBS group. Also, CLP increased the synthesis of NF- $\kappa$ B and TLR4 proteins while decreasing the synthesis of TRIM40 compared with control group (Fig. 5B). In the CLP + acetic acid group, the synthesis of TRIM40, NF- $\mathrm{B}$ and TLR4 proteins were upregulated compared with the control group. The results suggested that acetic acid could increase the expression of TRIM40 and decrease the expression of NF- $\kappa \mathrm{B}$ and TLR4. Additionally, acetic acid may alleviate the inflammatory response in septic mice by inhibiting the activity of the TLR4 signaling pathway. No significant differences were identified between the control + acetic acid and control groups.

Acetic acid reduces supernatant inflammatory factors levels in peritoneal macrophages. To get a better understanding of how acetic acid inhibited the inflammatory response induced by sepsis, the authors of the current study investigated the inflammatory factors levels in the supernatant of peritoneal macrophages. Following the incubation with LPS, 

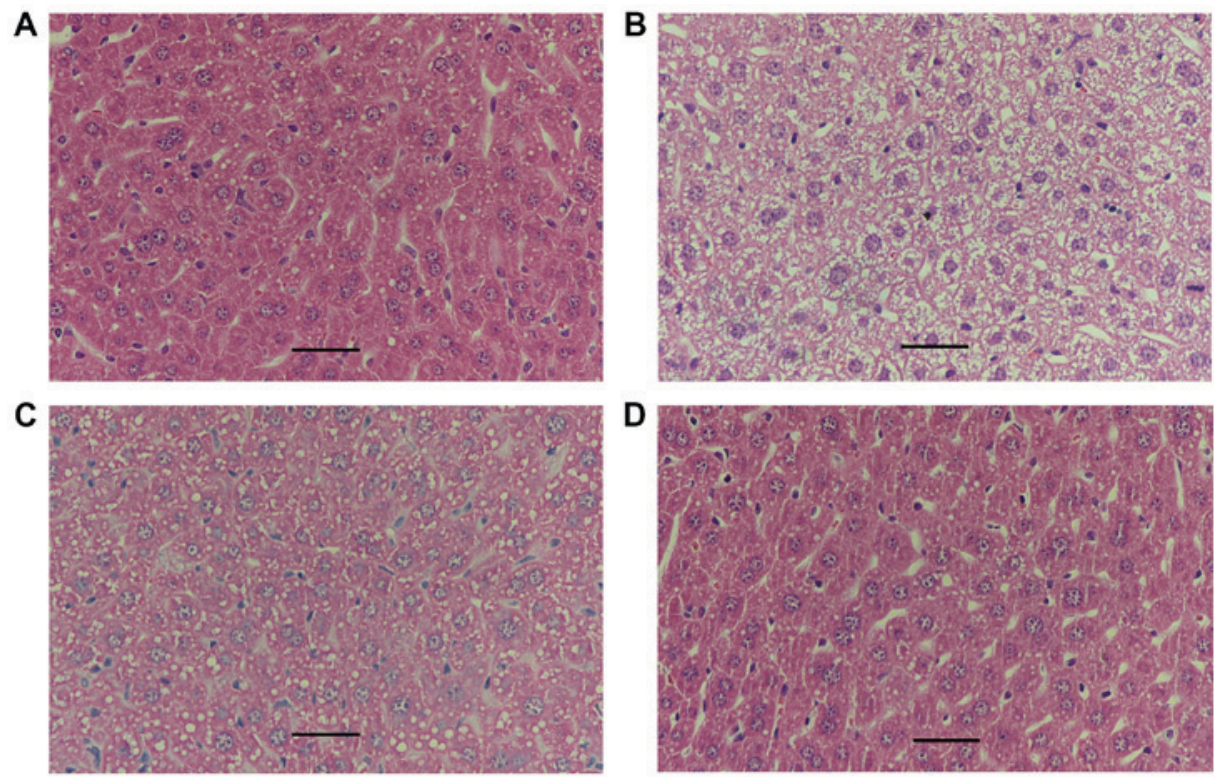

Figure 4. Acetic acid treatment attenuates pathological changes in the livers of CLP-model mice. Liver tissue in the (A) control, (B) CLP + PBS, (C) CLP + acetic acid and (D) control + acetic acid groups. Scale bar $=100 \mu \mathrm{m}$. CLP, cecal ligation and puncture.

A

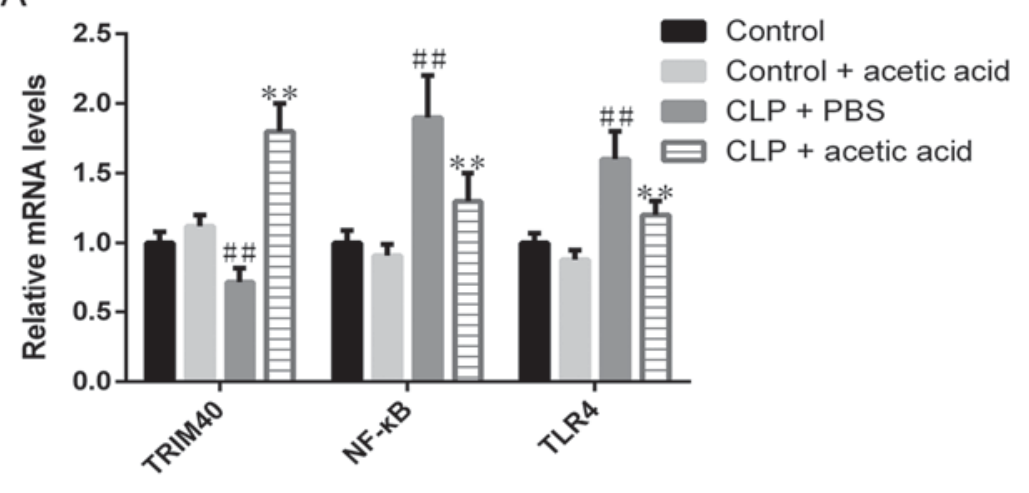

B

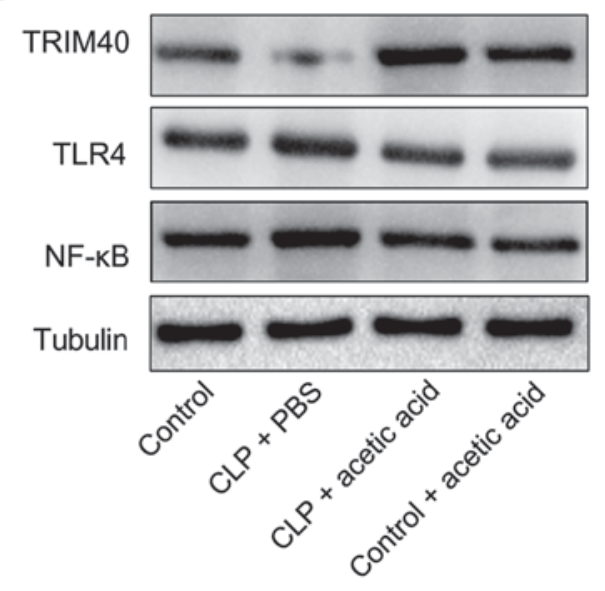

Figure 5. Acetic acid decreases NF- $\kappa$ B and TLR4, and increases TRIM40 levels in CLP-model mice. The (A) mRNA levels and (B) protein levels of NF- $\kappa$ B,

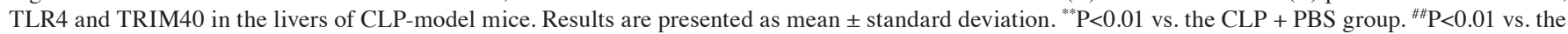
control group. CLP, cecal ligation and puncture; TRIM40, tripartite motif-containing protein 40; NF- $\kappa$ B, nuclear factor- $\kappa$ B; TLR4, Toll-like receptor 4.

the secretion of IL-6, IL-10 and TNF- $\alpha$ increased 159, 123 and $146 \%$, respectively, compared with the control group (Fig. 6). The results demonstrated that LPS may stimulate the synthesis and secretion of cytokines. IN the LPS + acetic acid group, the secretion of IL- 6 and TNF- $\alpha$ significantly decreased by 30 and $36 \%$, respectively, and the secretion of IL-10 significantly increased by $53 \%$, compared with the LPS group. The results suggested that inflammation induced by LPS was attenuated by acetic acid and that acetic acid may regulate the secretion of cytokines in macrophages. However, acetic acid had no significant effects on normal macrophages. When peritoneal macrophages were treated with LPS + acetic acid + TRIM40 siRNA, the secretion of IL- 6 and TNF- $\alpha$ significantly decreased while the secretion of IL-10 significantly increased compared with the LPS group.
Acetic acid upregulates the expression of TRIM40 and TRIM40 may inhibit the activity of TLR4 signal pathway in peritoneal macrophages. To assess the role of TRIM40 in the TLR4 signaling pathway, the mRNA levels and protein expression levels of TRIM40, NF- $\kappa \mathrm{B}$ and TLR4 were measured. The results of the RT-qPCR analysis demonstrated that the transfections were successful as incubating cells with siTRIM40 significantly decreased the mRNA expression of TRIM40 compared with the control group (Fig. 7A). In the LPS group, the expression of TRIM40 significantly decreased while the expression of NF- $\kappa \mathrm{B}$ and TLR4 significantly increased compared with the control group (Fig. 7B). It was also demonstrated that the mRNA level of TRIM40 of LPS-stimulated cells significantly increased by 1.9 -fold when treated with acetic acid, while levels of $\mathrm{NF}-\kappa \mathrm{B}$ and TLR4 significantly decreased by 42 and 33\%, respectively, 

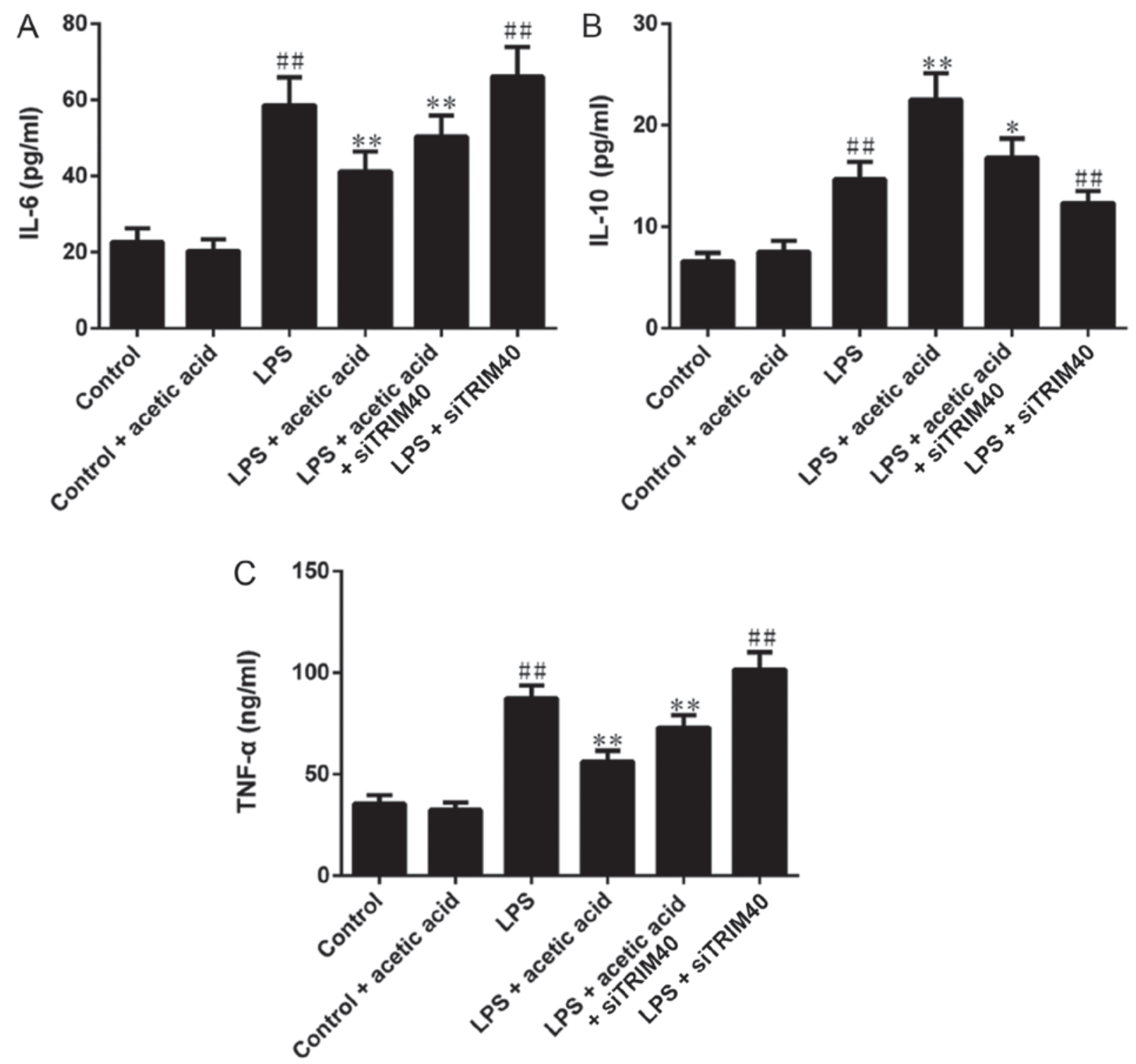

Figure 6. Acetic acid reduces supernatant inflammatory factors levels in peritoneal macrophages. Protein concentrations for (A) IL-6, (B) IL-10 and (C) TNF- $\alpha$ were measured using ELISA kits ( $\mathrm{n}=6$ mice/group). Results are presented as mean \pm standard deviation. ${ }^{*} \mathrm{P}<0.05,{ }^{* * *} \mathrm{P}<0.01$ vs. the LPS group. ${ }^{\# \#} \mathrm{P}<0.01$ vs. the control group. IL, interleukin; TNF- $\alpha$, tumor necrosis factor $\alpha$; LPS, lipopolysaccharide; TRIM40, tripartite motif-containing protein 40 ; si, small interfering RNA.

compared with the LPS group. When LPS-stimulated peritoneal macrophages were treated with acetic acid and siTRIM40, the expression of TRIM40 significantly reduced compared with the LPS group. Additionally, the expression levels of NF- $\kappa \mathrm{B}$ and TLR4 increased by 1.6- and 1.3-fold, respectively, compared with the LPS + acetic acid group. When compared with the LPS group, the expression levels of TLR4 and NF- $\kappa$ B were significantly increased in the LPS + siTRIM40 group. All these results suggested that acetic acid could promote the expression of TRIM40 and that TRIM40 may inhibit the activity of the TLR4 signaling pathway in peritoneal macrophages. Additionally, the protein expression trends were similar to the mRNA levels (Fig. 7C). The level of TRIM40 in the LPS + acetic acid group was increased, while the levels of NF- $\kappa \mathrm{B}$ and TLR4 decreased compared with the LPS group. After treating the LPS + acetic acid group with siTRIM40, the levels of NF- $\kappa$ B and TLR4 markedly increased.

\section{Discussion}

In the current study, it was demonstrated that acetic acid could alleviate the inflammatory response and liver injury in CLP-model mice by increasing the expression of TRIM40, and TRIM40 could regulate the activity of the TLR4 signaling pathway. To illustrate the interaction between TRIM40 and the TLR4 signaling pathway, LPS-induced peritoneal macrophages were observed following the alteration of TRIM40 levels. The results suggested that TRIM40 may act on as decreasing TRIM40 expression upregulated the activity of the TLR4 signaling pathway; the protective effect of acetic acid was reversed when TRIM40 was silenced. As a result, the authors of the current study hypothesized that acetic acid could inhibit inflammation and protect liver in septic mice mainly by enhancing the expression of TRIM40.

Acetic acid, as a type of common chemical compound, has been gradually receiving substantial attention and interest in 
A

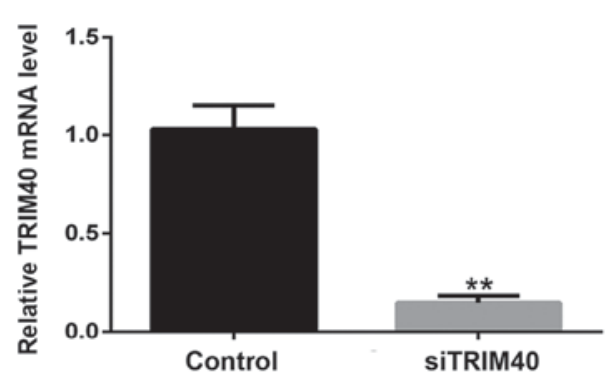

B

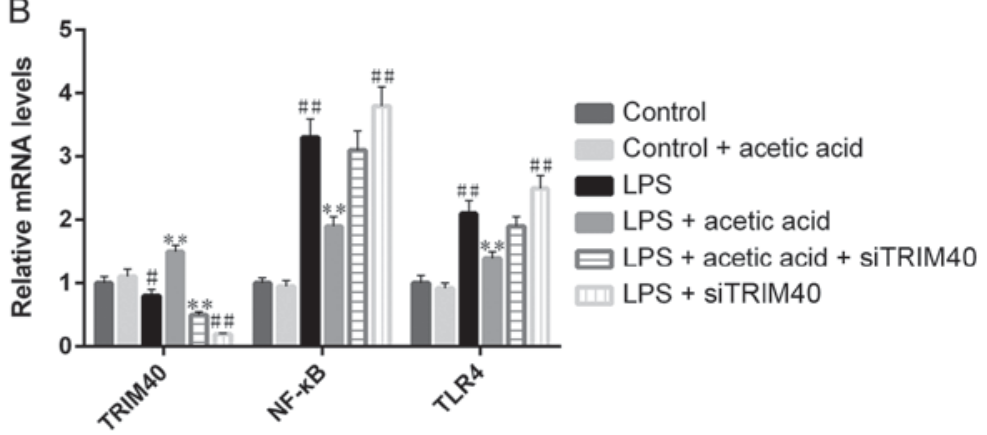

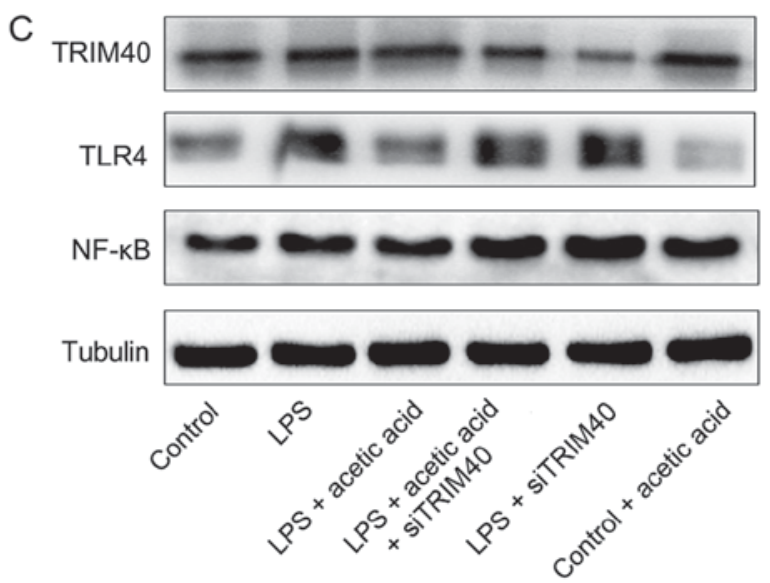

Figure 7. Acetic acid upregulates the expression of TRIM40 and TRIM40 may inhibit the activity of the TLR4 signaling pathway in peritoneal macrophages. (A) Relative mRNA expression of TRIM40. (B) Relative mRNA and (C) protein expression levels of TRIM40, NF- $\kappa$ B and TLR4 in peritoneal macrophages. Results are presented as mean \pm standard deviation. ${ }^{* *} \mathrm{P}<0.01$ vs. the LPS group; ${ }^{*} \mathrm{P}<0.05,{ }^{\# \#} \mathrm{P}<0.01$ vs. the control group. TRIM40, tripartite motif 40 ; NF- $\kappa \mathrm{B}$, nuclear factor- $\kappa \mathrm{B}$; TLR4, Toll-like receptor 4; si, small interfering RNA.

recent years. Acetic acid is the major ingredient in vinegar, and has been reported to be helpful for preventing metabolic syndrome in rats and human (33). In addition, vinegar has also revealed to be effective in anti-hypercholesterolemia, anti-hyperglycemia, anti-hypertension, anti-cancer and anti-inflammation treatment (34-36). Beh et al (33) revealed that synthetic acetic acid vinegar and Nipa vinegar could potentially alleviate obesity by altering inflammation, lipid metabolism and gut microbe composition in high-fat-diet-induced obese mice. According to the aforementioned study, synthetic acetic acid vinegar and Nipa vinegar treatments significantly suppressed the expression of inducible nitric oxide synthase (iNOS) in the liver, and reduced the serum lactate dehydrogenase level when compared with the untreated obese group. Additionally, Nipa vinegar contributed to improved anti-inflammation treatment by suppressing the expression of NF- $\kappa \mathrm{B}$ and iNOS (37). These results may be attributable to the upregulation of adiponectin by Nipa vinegar, as adiponectin inhibits inflammation by suppressing the activation of NF- $\kappa \mathrm{B}(37)$.

Yamashita (34) also determined that exogenously-administered acetic acid influenced lipid metabolism in the liver and skeletal muscles, and alleviated obesity and obesity-linked type 2 diabetes. To illuminate the protective effect of pineapple vinegar, Mohamad et al (35) determined that oral administration of pineapple vinegar restored liver antioxidant levels, and reduced serum enzyme biomarker levels, the expression of inflammatory factors and the liver protein, cytochrome $\mathrm{P} 450$, in mice with paracetamol-induced liver damage. As the major ingredient in different types of vinegars, acetic acid may have potential in anti-inflammation treatment and thus protect of liver. Therefore, the authors investigated the possibility of using acetic acid to inhibit the inflammatory response and decrease liver injury in septic mice, and the effectiveness of acetic acid was verified in studies by our group.

The current study demonstrated that the expression of TRIM40 was downregulated in septic mice and this phenomenon could be reversed with intravenous injections of acetic acid. Noguchi et al (38) revealed that TRIM40 was highly expressed in the normal gastrointestinal tract and bound to Nedd8, which was conjugated to target proteins by neddylation. The aforementioned study also determined that TRIM40 promoted the neddylation of $\mathrm{NF}-\kappa \mathrm{B}$ essential modulator, which is a crucial regulator in $\mathrm{NF}-\kappa \mathrm{B}$ activation. As a result, TRIM40 could inhibit the activity of NF- $\kappa$ B. This finding was also verified in the current study. Additionally, Noguchi et al (38) observed that the expression of TRIM40 was downregulated in the gastrointestinal tract and chronic inflammatory lesions of the gastrointestinal tract. The results suggested that, in the gastrointestinal tract, TRIM40 could prevent inflammation-associated carcinogenesis. In comparison, the expression of TRIM40 was decreased in CLP-model mice and LPS-treated peritoneal macrophages in the current study. However, the expression of TRIM40 increased significantly following acetic acid treatment. Therefore, the authors 
of the current study hypothesized that acetic acid may alleviate inflammation by upregulating the expression of TRIM40. Then, the authors performed further experiments to elucidate the relationship between TRIM40 and the TLR4 signaling pathway. When TRIM40 was silenced, the protective effect of acetic acid in reducing inflammation was severely weakened and the expression levels of inflammatory cytokines were increased. The results suggested that TRIM40 could be the major target for acetic acid to function as protective factor in septic mice.

Several cytokines have been correlated with the severity of sepsis (39). For example, IL-6 and TNF- $\alpha$ are the major inflammatory mediators that are significantly elevated in sepsis $(10,40)$. Excessive generation of cytokines can be regulated by the activation of certain signaling pathways, including TLR4 and p38 mitogen-activated protein kinase $(40,41)$. The TLR4 signaling pathway has been demonstrated to upregulate in sepsis and the expression of $\mathrm{NF}-\kappa \mathrm{B}$ also increases, since it is the downstream intracellular molecule of the TLR4 signaling pathway (42). The overexpression of cytokines demonstrated that they caused liver injury by activating complex signaling cascades (43). Thus, the excessive inflammatory response and associated liver injury may be ameliorated by suppressing the generation of cytokines and associated signaling pathways in sepsis. Several studies previously had demonstrated the role of TLRs in the production of cytokines and the activation of inflammatory cascades in sepsis $(44,45)$.

A number of studies investigated the involvement of $\mathrm{NF}-\kappa \mathrm{B}$ in sepsis-induced liver injury $(40,41)$. Feng et al $(46)$ demonstrated that the degradation of $N F-\kappa B$ inhibitor $\alpha$ $(\mathrm{I} \kappa \mathrm{B}-\alpha)$ and the accumulation of $\mathrm{NF}-\kappa \mathrm{B}$ in the nucleus increased in septic mice, and roflumilast alleviated liver injury by inhibiting the expression of $N F-\kappa B$ and degradation of I $\kappa \mathrm{B}-\alpha$. Those results suggested that $\mathrm{NF}-\kappa \mathrm{B}$ is closely associated with liver injury in septic mice and liver injury was ameliorated by inhibiting the expression of NF- $\mathrm{BB}$. In the current study, the authors revealed that liver injury was reduced following acetic acid treatment and the expression of NF- $\kappa \mathrm{B}$ was markably decreased. In conclusion, acetic acid may alleviate liver injury in septic mice by suppressing the production of cytokines and inhibiting the TLR4 signaling pathway.

In summary, the experiments in the current study indicate the effectiveness of acetic acid in attenuating inflammation and decreasing liver injury in septic mice by upregulating the expression of TRIM40. TRIM40 suppressed the production and secretion of cytokines, including IL- 6 and TNF- $\alpha$, increased the expression of IL-10, alleviated liver damage, inhibited the activity of TLR4 signal pathway and improved the survival rate in septic mice. Acetic acid treatment reduced inflammation and decreased the expression levels of inflammatory cytokines. When TRIM40 was silenced, the protective effects of acetic acid were reversed. TRIM40 is possibly the predominant target of acetic acid, allowing acetic acid to function as protective factor in septic mice. However, further studies are required to illustrate the mechanism of alleviation of inflammation by acetic acid and whether other factors are affected by alterations in TRIM40 expression. The findings in the current study provide novel insights into the pharmacological activities of acetic acid as a novel strategy for the treatment of sepsis.

\section{Acknowledgements}

Not applicable.

\section{Funding}

No funding received.

\section{Availability of data and materials}

Data and materials can be obtained from corresponding author upon reasonable request.

\section{Authors' contributions}

HY and LM performed the cell studies and wrote the manuscript. DA, NH and HL performed the animal studies. XS performed the analysis of the data. XP designed the study.

\section{Ethics approval and consent to participate}

The experiment was approved by the Ethics Committee in Qingdao University (Qingdao, China).

\section{Patient consent for publication}

Not applicable.

\section{Competing interests}

The authors declare that they have no competing interests.

\section{References}

1. Singer M, Deutschman CS, Seymour CW, Shankar-Hari M, Annane D, Bauer M, Bellomo R, Bernard GR, Chiche JD, Coopersmith CM, et al: The third international consensus definitions for sepsis and septic shock (sepsis-3). JAMA 315: 801-810, 2016.

2. Dellinger RP, Levy MM, Rhodes A, Annane D, Gerlach H, Opal SM, Sevransky JE, Sprung CL, Douglas IS, Jaeschke R, et al: Surviving sepsis campaign: International guidelines for management of severe sepsis and septic shock: 2012. Crit Care Med 41: 580-637, 2013.

3. Dombrovskiy VY, Martin AA, Sunderram J and Paz HL: Rapid increase in hospitalization and mortality rates for severe sepsis in the United States: A trend analysis from 1993 to 2003. Crit Care Med 35: 1244-1250, 2007.

4. Martin-Loeches I, Levy MM and Artigas A: Management of severe sepsis: Advances, challenges, and current status. Drug Des Devel Ther 9: 2079-2088, 2015.

5. Sagy M, Al-Qaqaa Y and Kim P: Definitions and pathophysiology of sepsis. Curr Probl Pediatr Adolesc Health Care 43: 260-263, 2013.

6. Gotts JE and Matthay MA: Sepsis: Pathophysiology and clinical management. BMJ 353: i1585, 2016.

7. Vincent JL, Marshall JC, Namendys-Silva SA, Francois B, Martin-Loeches I, Lipman J, Reinhart K, Antonelli M, Pickkers P, Njimi H, et al: Assessment of the worldwide burden of critical illness: The intensive care over nations (ICON) audit. Lancet Respir Med 2: 380-386, 2014.

8. Adhikari NK, Fowler RA, Bhagwanjee S and Rubenfeld GD: Critical care and the global burden of critical illness in adults. Lancet 376: 1339-1346, 2010. 
9. Torio CM and Moore BJ: National inpatient hospital costs: The most expensive conditions by payer, 2013. HCUP Statistical Brief \#204. Agency for Healthcare Research and Quality, Rockville, MD, 2016. https://www.hcup-us.ahrq.gov/reports/statbriefs/sb204-Most-ExpensiveHospital-Conditions.jsp. Accessed April 28, 2016.

10. Angus DC and van der Poll T: Severe sepsis and septic shock. N Engl J Med 369: 840-851, 2013.

11. Blanco J, Muriel-Bombin A, Sagredo V, Taboada F, Gandia F, Tamayo L, Collado J, Garcia-Labattut A, Carriedo D, Valledor M, et al: Incidence, organ dysfunction and mortality in severe sepsis: A Spanish multicentre study. Crit Care 12: R158, 2008.

12. Nesseler N, Launey Y, Aninat C, Morel F, Malledant Y and Seguin P: Clinical review: The liver in sepsis. Crit Care 16: 235, 2012.

13. Brun-Buisson C, Meshaka P, Pinton P, Vallet B and EPISEPSIS Study Group: EPISEPSIS: A reappraisal of the epidemiology and outcome of severe sepsis in French intensive care units. Intensive Care Med 30: 580-588, 2004.

14. Bakker J, Grover R, McLuckie A, Holzapfel L, Andersson J, Lodato R, Watson D, Grossman S, Donaldson J and Takala J: Administration of the nitric oxide synthase inhibitor NG-methyl-L-arginine hydrochloride (546C 88 ) by intravenous infusion for up to 72 hours can promote the resolution of shock in patients with severe sepsis: Results of a randomized, double-blind, placebo-controlled multicenter study (study no. 144-002). Crit Care Med 32: 1-12, 2004.

15. Bellou A, Schaub B, Ting L and Finn PW: Toll receptors modulate allergic responses: Interaction with dendritic cells, $\mathrm{T}$ cells and mast cells. Curr Opin Allergy Clin Immunol 3: 487-494, 2003.

16. Biswas SK and Lopez-Collazo E: Endotoxin tolerance: New mechanisms, molecules and clinical significance. Trends Immunol 30: 475-487, 2009.

17. Zhang S, Yang N, Ni S, Li W, Xu L, Dong P and Lu M: Pretreatment of lipopolysaccharide (LPS) ameliorates D-GalN/LPS induced acute liver failure through TLR4 signaling pathway. Int J Clin Exp Pathol 7: 6626-6634, 2014.

18. Zhang YP, Pan CS, Yan L, Liu YY, Hu BH, Chang X, Li Q, Huang DD, Sun HY, Fu G, et al: Catalpol restores LPS-elicited rat microcirculation disorder by regulation of a network of signaling involving inhibition of TLR-4 and SRC. Am J Physiol Gastrointest Liver Physiol 311: G1091-G1104, 2016.

19. Tissieres P, Dunn-Siegrist I, Schappi M, Elson G, Comte R, Nobre V and Pugin J: Soluble MD-2 is an acute-phase protein and an opsonin for Gram-negative bacteria. Blood 111: 2122-2131, 2008.

20. Poltorak A, He X, Smirnova I, Liu MY, Van Huffel C, Du X, Birdwell D, Alejos E, Silva M, Galanos C, et al: Defective LPS signaling in $\mathrm{C} 3 \mathrm{H} / \mathrm{HeJ}$ and $\mathrm{C} 57 \mathrm{BL} / 10 \mathrm{ScCr}$ mice: Mutations in Tlr4 gene. Science 282: 2085-2088, 1998.

21. Reymond A, Meroni G, Fantozzi A, Merla G, Cairo S, Luzi L, Riganelli D, Zanaria E, Messali S, Cainarca S, et al: The tripartite motif family identifies cell compartments. EMBO J 20 2140-2151, 2001.

22. Hatakeyama S: TRIM proteins and cancer. Nat Rev Cancer 11: 792-804, 2011

23. Gack MU, Shin YC, Joo CH, Urano T, Liang C, Sun L, Takeuchi O, Akira S, Chen Z, Inoue S and Jung JU: TRIM25 RING-finger E3 ubiquitin ligase is essential for RIG-I-mediated antiviral activity. Nature 446: 916-920, 2007.

24. Miyajima N, Maruyama S, Bohgaki M, Kano S, Shigemura M, Shinohara N, Nonomura K and Hatakeyama S: TRIM68 regulates ligand-dependent transcription of androgen receptor in prostate cancer cells. Cancer Res 68: 3486-3494, 2008.

25. Kikuchi M, Okumura F, Tsukiyama T, Watanabe M, Miyajima N, Tanaka J, Imamura M and Hatakeyama S: TRIM24 mediates ligand-dependent activation of androgen receptor and is repressed by a bromodomain-containing protein, BRD7, in prostate cancer cells. Biochim Biophys Acta 1793: 1828-1836, 2009.

26. Institute of Laboratory Animal Resources (U.S.), Committee on Care and Use of Laboratory Animals, National Institutes of Health (U.S.) and Division of Research Resources: Guide for the Care and Use of Laboratory Animals. NIH Publication No. 85-23. U.S. Dept. of Health and Human Services, Public Health Service, National Insititutes of Health, Bethesda, MD, 1985.
27. National Research Council (US) Institute for Laboratory Animal Research: Guide for the Care and Use of Laboratory Animals. National Academies Press (US), Washington, DC, 1996.

28. Kawakami T, Koike A and Amano F: Induction of different activated phenotypes of mouse peritoneal macrophages grown in different tissue culture media. Cytotechnology 69: 631-642, 2017.

29. Awasthi A, Rathore G, Sood N, Khan MY and Lakra WS: Establishment of a leukocyte cell line derived from peritoneal macrophages of fish, Labeo rohita (Hamilton, 1822). Cytotechnology 67: 85-96, 2015.

30. Rittirsch D, Huber-Lang MS, Flierl MA and Ward PA Immunodesign of experimental sepsis by cecal ligation and puncture. Nat Protoc 4: 31-36, 2009.

31. Lemaitre E, Allee C, Vabret A, Eterradossi N and Brown PA: Single reaction, real time RT-PCR detection of all known avian and human metapneumoviruses. J Virol Methods 251: 61-68, 2018.

32. Ott LE and Carson S: Immunological tools: Engaging students in the use and analysis of flow cytometry and enzyme-linked immunosorbent assay (ELISA). Biochem Mol Biol Educ 42: 382-397, 2014.

33. Beh BK, Mohamad NE, Yeap SK, Ky H, Boo SY, JYH C, Tan SW, Ho WY, Sharifuddin SA, Long K and Alitheen NB: Anti-obesity and anti-inflammatory effects of synthetic acetic acid vinegar and Nipa vinegar on high-fat-diet-induced obese mice. Sci Rep 7: 6664, 2017.

34. Yamashita H: Biological function of acetic acid-improvement in obesity and glucose tolerance by acetic acid in type 2 diabetic rats. Crit Rev Food Sci Nutr 56: S171-S175, 2016.

35. Mohamad NE, Yeap SK, Lim KL, Yusof HM, Beh BK, Tan SW, Ho WY, Sharifuddin SA, Jamaluddin A, Long K, et al: Antioxidant effects of pineapple vinegar in reversing of paracetamol-induced liver damage in mice. Chin Med 10: 3, 2015.

36. Beh BK, Mohamad NE, Yeap SK, Lim KL, Wang YH, Yusof HM, Sharifuddin SA, Jamaluddin A, Long K and Alitheen NB: Polyphenolic profiles and the in vivo antioxidant effect of nipa vinegar on paracetamol induced liver damage. RSC Advance 6: 63304-63313, 2016.

37. Ouchi $\mathrm{N}$ and Walsh $\mathrm{K}$ : Adiponectin as an anti-inflammatory factor. Clin Chim Acta 380: 24-30, 2007.

38. Noguchi K, Okumura F, Takahashi N, Kataoka A, Kamiyama T, Todo S and Hatakeyama S: TRIM40 promotes neddylation of IKKgamma and is downregulated in gastrointestinal cancers. Carcinogenesis 32: 995-1004, 2011.

39. Jekarl DW, Kim JY, Lee S, Kim M, Kim Y, Han K, Woo SH and Lee WJ: Diagnosis and evaluation of severity of sepsis via the use of biomarkers and profiles of 13 cytokines: A multiplex analysis. Clin Chem Lab Med 53: 575-581, 2015.

40. Liang Y, Li X, Zhang X, Li Z, Wang L, Sun Y, Liu Z and Ma X: Elevated levels of plasma TNF-alpha are associated with microvascular endothelial dysfunction in patients with sepsis through activating the NF-kappaB and p38 mitogen-activated protein kinase in endothelial cells. Shock 41: 275-281, 2014.

41. Khakpour S, Wilhelmsen K and Hellman J: Vascular endothelial cell Toll-like receptor pathways in sepsis. Innate Immun 21: 827-846, 2015.

42. Chantratita N, Tandhavanant S, Seal S, Wikraiphat C, Wongsuvan G, Ariyaprasert P, Suntornsut P, Teerawattanasook N, Jutrakul Y, Srisurat N, et al: TLR4 genetic variation is associated with inflammatory responses in Gram-positive sepsis. Clin Microbiol Infect 23: 47.e1-47.e10, 2017.

43. Chan CC, Lee KC, Huang YH, Chou CK, Lin HC and Lee FY: Regulation by resveratrol of the cellular factors mediating liver damage and regeneration after acute toxic liver injury. J Gastroenterol Hepatol 29: 603-613, 2014.

44. Weighardt $\mathrm{H}$ and Holzmann B: Role of Toll-like receptor responses for sepsis pathogenesis. Immunobiology 212: 715-722, 2007.

45. Tian Y, Li Z, Shen B, Zhang Q and Feng H: Protective effects of morin on lipopolysaccharide/d-galactosamine-induced acute liver injury by inhibiting TLR4/NF-kappaB and activating Nrf2/HO-1 signaling pathways. Int Immunopharmacol 45: 148-155, 2017.

46. Feng H, Chen J, Wang H, Cheng Y, Zou Z, Zhong Q and Xu J: Roflumilast reverses polymicrobial sepsis-induced liver damage by inhibiting inflammation in mice. Lab Invest 97: 1008-1019, 2017. 